\title{
INSTRUMENTOS DE PARTICIPAÇÃO CIDADÃ NA CÂMARA DOS
} DEPUTADOS

\section{INSTRUMENTS OF CITIZEN PARTICIPATION IN THE HOUSE OF REPRESENTATIVES}

\author{
Robson Luiz Fialho Coutinho*
}

\begin{abstract}
Resumo: Analisa as ferramentas voltadas para a participação popular da Câmara dos Deputados. Serão analisadas as finalidades, formas de participação, funcionalidades existentes, benefícios e limitações das ferramentas a fim de identificar se essas ferramentas contribuem para aumentar a participação política e o engajamento cívico. Os canais de participação são: o Bate-papo, Debates no e-democracia, Enquetes, Fale com a ouvidoria, Fale com o deputado, Fale conosco, Redes sociais e Sua proposta pode virar lei. Conclui-se que os canais permitem o envio de opiniões, sugestões e críticas, porém são mínimas as possibilidades de participação do cidadão no processo decisório. Por isso, persiste o desafio aumentar o nível qualitativo da comunicação entre representantes e representados no sentido de dar maior poder ao cidadão.
\end{abstract}

Palavras-chave: Atividade legislativa; Câmara dos Deputados; Internet; Participação popular.

\begin{abstract}
This article is to analyze the tools geared towards popular participation of the Chamber of Deputies. Purposes, forms of participation, existing features, benefits and limitations of the tools will be analyzed in order to identify whether these tools help to increase political participation and civic engagement. Channels of participation are: chat, discuss on eDemocracy, Polls, Talk to the ombudsman, Talk to the Deputy, Talk to us, Social Networks and Your proposal can become law. We conclude that the channels allow the sending of opinions, suggestions and criticism, but are minimal opportunities for citizen participation in decision process. Therefore, the challenge remains to increase the qualitative level of communication between representatives and represented in order to give greater power to citizens.
\end{abstract}

Keywords: Legislative Activity; House of Representatives; Internet; Popular participation.

\footnotetext{
* Robson Luiz Fialho Coutinho, graduado em Administração pela Associação de Ensino Unificado do Distrito Federal (1992), pós-graduado em Desenvolvimento Gerencial pela Universidade de Brasília (2003), pós-graduado em Administração Legislativa pela Universidade Federal de Mato Grosso do Sul (2009) e aluno do Mestrado Profissional em Poder Legislativo da Câmara dos Deputados. É Analista Legislativo da Câmara dos Deputados (robson.coutinho@camara.leg.br).
} 


\section{Introdução}

O surgimento da Internet provocou uma revolução nos meios de comunicação. A rede mundial de computadores facilitou o envio e o recebimento de informações e o acesso de milhões de pessoas em todo o mundo a grandes repositórios de conhecimento.

Os novos recursos oferecidos pela rede mundial de computadores provocaram entusiasmo, expectativas e discussões sobre a possibilidade de haver um fortalecimento da participação da sociedade civil na política, por meio de debates, deliberações, troca de informações, acesso a bancos de dados públicos e maior aproximação entre agentes públicos e cidadãos.

A Internet trouxe grandes expectativas no que se refere às possibilidades de participação democrática. Muitos especialistas pensaram que a maioria das formas de ação política da esfera civil passaria a ser feita pela Internet (GOMES, 2008).

Alguns críticos identificaram que a infraestrutura de comunicação digital poderia aprofundar algumas injustiças sociais, uma vez que parte da população teria dificuldade de acesso às novas tecnologias. Além disso, a mesma infraestrutura poderia servir para tornar mais eficazes e potentes as ações de grupos mal intencionados e governos ditatoriais (MAIA, 2011).

As novas tecnologias oferecidas pela Internet facilitam a comunicação, a busca por informações e a manifestação livre de censuras sobre os mais diversos temas. Entretanto, para que o cidadão se interesse pela participação política é preciso que a sociedade e o Estado encontrem mecanismos não só capazes de incentivar a participação, mas que possam mostrar-se eficientes no acolhimento de parte das sugestões resultantes do processo participativo.

De acordo com Gomes (2008), a Internet possui um potencial inédito de interação, que pode proporcionar a comunicação direta entre os cidadãos e os políticos. Porém, para que a comunicação aconteça não basta a existência da tecnologia. É preciso que haja a motivação correta, o interesse e a disponibilidade das pessoas para participarem dos debates. Para Maia (2011), a Internet pode transformar a baixa participação política da esfera civil nas democracias contemporâneas. Para que isso ocorra, é preciso utilizar as ferramentas digitais com o objetivo de garantir e incrementar a participação nas esferas de decisão, a liberdade de expressão, a transparência pública e as experiências de democracia direta.

Segundo Barbosa (2009), a adoção intensiva das tecnologias de informação e comunicação pela administração pública evoluiu para o que é hoje chamado de governo eletrônico. O governo eletrônico favorece a melhoria dos serviços públicos, aumenta a eficiência e transparência e fomenta a participação democrática. Porém, é preciso investir na comunicação e facilidade de uso para que o cidadão compreenda, assimile e se aproprie dos benefícios dos serviços públicos eletrônicos. 
O debate sobre os benefícios e limites da comunicação digital para o fortalecimento da participação dos cidadãos nos conduz a uma análise de canais e ferramentas desenvolvidas com o objetivo de favorecer o debate e a participação do cidadão. Nesse sentido, o objetivo deste trabalho é analisar as ferramentas oferecidas pela Câmara dos Deputados para a participação cívica a fim de identificar os diferentes tipos de participação. Para cada ferramenta serão identificadas, com o apoio de textos publicados por outros autores, as finalidades, formas de participação, funcionalidades existentes, benefícios oferecidos e limitações. No caso da avaliação qualitativa, serão utilizados os requisitos democráticos e respectivas dimensões qualitativas propostas por Silva (2011) para avaliar o grau de comunicação que pode ser alcançado pelo uso do canal.

\section{Requisitos Democráticos}

De acordo com Silva (2011) existem três requisitos democráticos básicos a serem cumpridos pelas interfaces digitais do Estado para que possam contribuir com o bom funcionamento do sistema democrático contemporâneo: publicidade, responsividade e porosidade.

A publicidade tem por objetivo tornar o Estado mais transparente por meio da divulgação de informações, notícias, relatórios de gestão, entre outros, para que o cidadão possa compreender o funcionamento do Estado e monitorar as ações governamentais.

A responsividade tem a ver com o estabelecimento de um diálogo entre o Estado e o cidadão, que pode ocorrer por meio de uma resposta informativa a uma determinada questão, como também por meio de uma interação argumentativa entre cidadãos e agentes do Estado.

A porosidade caracteriza-se pela incorporação pelo Estado das sugestões feitas pelos cidadãos por meio de votações, sondagens de opinião, etc.

Na materialização dos três requisitos democráticos pelas interfaces digitais, Silva (2011) identifica cinco níveis qualitativos por meios dos quais os requisitos podem ser medidos, conforme são estabelecidas relações comunicativas mais densas. São eles: utilitário, informativo, instrutivo, argumentativo e decisório.

O estabelecimento dos níveis qualitativos permite que se faça uma gradação dos requisitos democráticos (do nível utilitário até o decisório) no sentido de tornar o Estado mais transparente, mais aberto ao diálogo e mais aberto à opinião pública.

Cada um dos três requisitos podem se materializar simultaneamente em diversos níveis, sendo que o nível decisório só existe no caso da porosidade, pois se trata de uma relação imperativa do cidadão para o Estado.

Os requisitos democráticos e alguns exemplos concretos relativos aos respectivos níveis podem ser visualizados no quadro abaixo. 
Quadro 1 - Requisitos democráticos e dimensões qualitativas

\begin{tabular}{|c|c|c|c|}
\hline & $\begin{array}{c}\text { Publicidade } \\
\text { (transparência) }\end{array}$ & $\begin{array}{c}\text { Responsividade } \\
\text { (diálogo) }\end{array}$ & $\begin{array}{c}\text { Porosidade } \\
\text { (incorporação de } \\
\text { sugestões dos cidadãos) } \\
\end{array}$ \\
\hline Utilitário & $\begin{array}{l}\text { Ferramentas de } \\
\text { busca, mapa do } \\
\text { site }\end{array}$ & $\begin{array}{l}\text { Emissão de } \\
\text { burocráticos, } \\
\text { online, etc. }\end{array}$ & $\begin{array}{l}\text { Ferramentas de coleta de } \\
\text { preferência de perfis }\end{array}$ \\
\hline Informativo & $\begin{array}{l}\text { Notícias, } \\
\text { propagandas, } \\
\text { informativos, } \\
\text { diário oficial, } \\
\text { etc. }\end{array}$ & $\begin{array}{l}\text { Ferramentas de e-mail, } \\
\text { formulários e chats para } \\
\text { tirar dúvidas ou solicitar } \\
\text { respostas, etc. }\end{array}$ & $\begin{array}{l}\text { Sondagens de opinião ou } \\
\text { questionário de marcação } \\
\text { objetiva }\end{array}$ \\
\hline Instrutivo & $\begin{array}{l}\text { Textos sobre a } \\
\text { história } \quad \mathrm{e} \\
\text { organização da } \\
\text { instituição, } \\
\text { páginas sobre o } \\
\text { funcionamento } \\
\text { da organização, } \\
\text { etc. }\end{array}$ & $\begin{array}{l}\text { Fóruns online, chats ou } \\
\text { lista de discussão pública, } \\
\text { para esclarecer uma } \\
\text { campanha, um projeto, uma } \\
\text { ação ou o próprio } \\
\text { funcionamento do } \\
\text { etc. }\end{array}$ & $\begin{array}{l}\text { Formulários online ou } \\
\text { ferramentas similares para } \\
\text { colher a opinião textual do } \\
\text { cidadão sobre um projeto, } \\
\text { uma ação ou atividade do } \\
\text { Estado }\end{array}$ \\
\hline Argumentativo & $\begin{array}{l}\text { Textos, } \\
\text { documentos, } \\
\text { relatórios, } \\
\text { balancetes, } \\
\text { prestação de } \\
\text { contas, etc. }\end{array}$ & 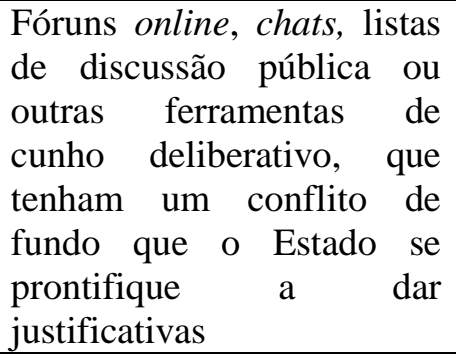 & $\begin{array}{l}\text { Formulários online ou } \\
\text { ferramentas voltadas para } \\
\text { colher propostas } \\
\text { discursivamente } \\
\text { estruturadas que serão } \\
\text { levadas em conta no } \\
\text { processo da decisão } \\
\text { política }\end{array}$ \\
\hline Decisório & - & - & $\begin{array}{lr}\text { Voto, plebiscito } & \text { e } \\
\text { referendo mediados } & \text { por } \\
\text { ferramentas } & \text { de } \\
\text { comunicação } & \\
\end{array}$ \\
\hline
\end{tabular}

Fonte: Adaptado pelo autor, de Silva (2011)

\section{Ferramentas de participação}

No portal institucional da Câmara dos Deputados existem alguns serviços voltados para a participação do cidadão reunidos na opção "Participe" do Menu principal. São eles: Batepapos, Debates no e-Democracia, Enquetes, Fale com a Ouvidoria, Fale com o Deputado, Fale conosco, Redes sociais e Sua proposta pode virar lei.

Cada um desses instrumentos possibilita uma forma diferente de participação e de interação com parlamentares ou com algum órgão administrativo da Câmara dos Deputados.

As Enquetes, Fale com a Ouvidoria, Fale com o Deputado, Fale conosco, Iniciativa popular e Sugestões legislativas à Comissão de Legislação Participativa são consideradas ferramentas de interação bilateral, pois permitem a comunicação entre dois atores. São

\footnotetext{
${ }^{1}$ Durante a elaboração do texto foi incluída a opção "Eventos" no menu Participe. Essa opção apresenta uma lista de eventos (seminários, comemorações, lançamentos etc.) programados para ocorrer nas dependências da Câmara dos Deputados. Essa ferramenta não foi objeto de estudo deste trabalho.
} 
consideradas ferramentas multilaterais o Bate-papo, Debates no e-Democracia e as Redes sociais, uma vez que envolvem a comunicação entre vários atores (PERNA, 2010).

\subsection{Bate-papos}

A opção Bate-papos conduz o usuário para um serviço denominado Videochat da área de notícias do portal. O usuário pode participar de um debate, desde que haja uma sala de batepapo "aberta".

Os videochats ou e-democracias são discussões sobre uma proposta legislativa, com a presença de um parlamentar. Um Deputado é entrevistado ao vivo por um repórter da TV Câmara, enquanto os usuários presentes na sala de bate-papo acompanham a entrevista pela Internet e digitam suas dúvidas e comentários sobre o tema.

Um mediador orienta os internautas sobre o debate e encaminha algumas perguntas para o repórter que está entrevistando o parlamentar. Cada bate-papo tem duração de mais ou menos uma hora e todos os encontros realizados ficam disponíveis para consulta posterior na página da Câmara dos Deputados.

O bate-papo foi criado em 2005 e em 2008 passou a apresentar a transmissão de imagens, passando a se chamar Videochat (PERNA, 2010). De março de 2005 a maio de 2010 foram realizado 54 chats, o que resulta numa média de 9 por ano, com a presença média de 80 participantes.

Para Nakamura (2013), como os temas selecionados para o bate-papo são polêmicos ou de grande interesse, os participantes expõem seus diferentes pontos de vista muitas vezes de forma bastante acalorada. As dúvidas podem ser respondidas pelo Deputado convidado e também pelos participantes, que conversam entre si. Marques (2010) assevera que no bate-papo o usuário tem apenas alguns instantes para se expressar, o que impede o aprofundamento do debate e o maior desenvolvimento das ideias e reflexões.

Conforme avaliação feita por Stabile (2012) sobre os canais de interatividade e participação da Câmara dos Deputados, 62,2\% dos usuários consideram o bate-papo uma ferramenta satisfatória, sendo $8,1 \%$ de usuários muito satisfeitos e $54,1 \%$ de usuários satisfeitos. Ainda conforme Stabile (2012), os canais de interatividade (bate-papo e e-Democracia) possuem piores índices de satisfação que os canais de participação e de informações. Isso se deve principalmente a ausência de respostas por parte dos parlamentares.

A ferramenta de bate-papo permite uma interação entre o parlamentar e o cidadão, uma vez que as perguntas podem ser encaminhadas pelo moderador para o entrevistador. Além disso, existe uma interação entre os próprios usuários, cada um expressando seu ponto de vista e defendendo suas ideias. Porém, o grande número de participantes e o formato do serviço impossibilitam que todas as questões sejam respondidas. 
Alguns pontos que podem ser melhorados são a oferta de mais bate-papos e a publicação antecipada dos próximos encontros previstos, para que os interessados possam se programar para participar do evento.

\subsection{Debates no e-Democracia}

O e-Democracia é um portal desenvolvido pela Câmara dos Deputados com a intenção de incentivar a participação da sociedade, por meio da Internet, nos debates sobre os principais temas em discussão no país. De acordo com Faria (2012), o portal e-Democracia é um espaço interativo criado em 2009 para estimular a contribuição de cidadãos e organizações civis no processo legislativo federal.

Em 2012 o portal e-Democracia recebeu 222.443 visitas de 135.587 pessoas. De janeiro a dois de agosto de 2013 o site recebeu 146.527 visitas, tendo sido acessado por 123.859 pessoas. O tempo médio de cada visita em 2012 foi de 4:25 minutos enquanto no primeiro semestre de 2013 o tempo médio foi de 1:53 minutos (BRASIL, 2013e).

O portal é dividido em dois espaços de participação, as comunidades legislativas e o espaço livre. Nas comunidades legislativas os usuários podem participar de debates sobre temas que estão em discussão na Câmara dos Deputados. No espaço livre o usuário pode criar um tema e iniciar uma discussão. O e-Democracia permite a participação dos usuários por meio de fóruns, bate-papos, wikilegis e pela biblioteca virtual. O Fórum é o local onde ocorre a maior discussão de ideias. Cada comunidade possui um fórum próprio, dividido por tópicos para facilitar o debate. Após selecionar um tópico, é possível visualizar os comentários publicados e inserir seus próprios comentários. Também é possível marcar o comentário de alguém com as seguintes opções: "gostei”, "não gostei” e "impróprio". Para cada marcação "gostei” o comentário recebe um voto positivo e para cada marcação "não gostei", o comentário recebe um voto negativo.

O bate-papo ocorre no período em que a matéria está em discussão na Câmara dos Deputados. As salas de bate-papo ficam abertas por um determinado período, durante o qual o usuário pode interagir em tempo real com os demais membros da comunidade e com os Deputados participantes. Se o bate-papo ocorrer durante um Seminário ou Audiência Pública de uma Comissão da Câmara dos Deputados, os participantes podem acompanhar ao debate, comentar e também fazer perguntas que podem vir a ser respondidas em tempo real pelos debatedores.

No Wikilegis os usuários podem propor alterações no texto da proposição (projeto de lei, projeto de código, projeto de lei complementar etc.) que está em discussão na Câmara dos Deputados. O texto original da proposição é publicado e os usuários podem comentar e sugerir alterações no texto do projeto. 
Na discussão sobre o Marco Civil da Internet ${ }^{2}$, que trata dos princípios norteadores da rede mundial de computadores no Brasil, foram feitas 374 contribuições pelo e-Democracia, das quais seis foram acatadas pelo relator do projeto, Deputado Alessandro Molon (PT/RJ). Foram realizadas sete audiências públicas e seminários interativos. Entre abril e maio de 2012 o portal recebeu cerca de doze mil acessos de usuários interessados nesse tema (BRASIL, 2013e).

A biblioteca virtual é a área de armazenamento de documentos sobre determinado tema. O usuário pode ter acesso à legislação, proposições, artigos, notas de audiências públicas, vídeos etc. Para Perna (2010), um dos desafios da ferramenta é fazer a gestão das informações que chegam de maneira difusa, por meio do fórum, bate-papo e ferramenta wiki. Outro desafio destacado por Nakamura (2013) é a ausência de respostas a manifestações direcionadas aos parlamentares, o que gera dúvidas sobre o destino das ideias apresentadas pelos usuários. Em algumas comunidades, existem vídeos gravados por Deputados incentivando a participação dos usuários nos debates ou agradecendo pelas colaborações e manifestações publicadas. Porém, a participação direta de um parlamentar no debate pelo Bate-papo não é muito comum, visto que a maioria não possui familiaridade com esse tipo de ferramenta e pelo fato de que eles precisam acompanhar o andamento da reunião da Comissão.

De acordo com Stabile (2012), é preciso melhorar a comunicação dos resultados obtidos nas discussões, investir na melhoria da ferramenta para tornar a participação mais fácil e criar parcerias com entidades da sociedade civil. Ainda assim, o e-Democracia é o mais avançado instrumento de democracia eletrônica existente no Brasil.

Trata-se da ferramenta com o maior nível de requisitos democráticos dentre as disponíveis no portal de participação, uma vez que as contribuições feitas pelos cidadãos podem vir a interferir no processo legislativo.

\subsection{Enquetes}

As enquetes são votações realizadas por meio do Portal sobre assuntos de grande interesse ou relevância, relativos a algum tema que esteja sendo discutido ou votado na Câmara dos Deputados. O objetivo da ferramenta é promover a integração entre a Câmara dos Deputados e os usuários do portal (BRASIL, 2013d).

Em setembro de 2013 haviam 23 enquetes ativas, nas quais era possível votar e verificar a quantidade de votos para cada uma das opções disponíveis. Entre as enquetes ativas a "Revogação do estatuto do desarmamento" possuía o maior número de votos: 71.563 enquanto que a "Transmissão de lutas de MMA na TV" possuía somente 489 votos. Antes de votar, o usuário pode obter informações sobre o tema objeto da enquete. Basta clicar na opção "clique

\footnotetext{
${ }^{2}$ Disponível em: <www.edemocracia.camara.gov.br/web/marco-civil-da-internet $>$. Acesso em: 08 out. 2013.
} 
aqui para saber mais" e abre-se uma página contendo mais detalhes sobre o assunto. Se desejar, o usuário pode escrever comentários sobre a enquete.

As enquetes são divulgadas pela Agência Câmara de Notícias, que publica uma matéria com detalhes sobre o tema e sobre a proposição em discussão. Também é possível ter acesso ao texto integral da proposição. A Agência Câmara faz reportagens sobre algumas enquetes enquanto ainda estão abertas, para divulgar a pesquisa e obter maior participação. As mais votadas também são objeto de notícia após o seu encerramento. Cada enquete é encerrada automaticamente após quinze dias consecutivos sem receber votos.

Stabile (2012) esclarece que as enquetes não possuem valor legal, mas são um incentivo para que os usuários possam opinar sobre determinados temas. Na avaliação sobre os canais de interatividade e participação da Câmara dos Deputados, a ferramenta obteve um índice de satisfação de $82,2 \%$, sendo $15,5 \%$ muito satisfeito e $66,7 \%$ de usuários satisfeitos.

As enquetes não possuem valor científico, uma vez que a pesquisa não obtém, em termos estatísticos, uma amostra representativa da população. Por essa razão, se algum Deputado vier a se interessar pelos resultados das enquetes, não terá em mãos a opinião da maioria da população, mas apenas os votos dos que estão mais motivados a votar e têm acesso à página da Câmara dos Deputados. Apesar disso, pode-se dizer que a ferramenta cumpre a sua principal finalidade, que é a de promover a participação do cidadão.

Apesar de apresentar uma votação, a Enquete é uma ferramenta de sondagem de opinião que agrega informações sobre um tema relevante em debate na Câmara dos Deputados.

\subsection{Fale com a Ouvidoria}

A Ouvidoria da Câmara dos Deputados foi criada em 2001 e é composta por três Deputados, sendo um Ouvidor-Geral e dois Ouvidores substitutos, nomeados pelo Presidente da Câmara dos Deputados para um mandato de dois anos. O Ombudsman ou Ouvidor representa os interesses do cidadão junto às instituições públicas (BRASIL, 2010).

A Ouvidoria é apresentada como um "órgão consultivo da Presidência da Câmara dos Deputados" (BRASIL, 2010). Porém, no organograma da Câmara dos Deputados ${ }^{3}$, a Ouvidoria Parlamentar aparece como um órgão ligado diretamente ao Plenário e não à Presidência. A Resolução que cria a Ouvidoria Parlamentar estabelece que o Presidente é encarregado de designar o Ouvidor e seus substitutos, mas não determina a subordinação hierárquica do órgão.

O órgão em questão é uma porta aberta para a cidadania, um canal de comunicação direta entre o cidadão e os Deputados, um termômetro da opinião da sociedade sobre a atuação parlamentar. Por meio dela o cidadão pode colaborar com sugestões para a melhoria da qualidade dos serviços prestados pela Câmara dos Deputados (BRASIL, 2010).

\footnotetext{
${ }^{3}$ Disponível em <www.camara.leg.br/a-camara/estruturaadm>
} 
Na página do Fale Conosco e do Fale com o Deputado o usuário é informado que deve utilizar o Fale com a Ouvidoria para "comunicar mau funcionamento ou irregularidades nas atividades e serviços administrativos da Câmara dos Deputados". De fato, a Ouvidoria é responsável por receber, examinar e encaminhar aos órgãos competentes reclamações e denúncias (BRASIL, 2001). O glossário de termos referentes à gestão do relacionamento esclarece que reclamação é uma "mensagem em que o cidadão comunica irregularidades ou mau funcionamento de atividades administrativas e serviços na Câmara dos Deputados" e denúncia é uma "mensagem em que o cidadão comunica ilegalidades ou abuso de poder no âmbito da Câmara dos Deputados, que não sejam de conhecimento público" (BRASIL, 2013a).

A partir da opção Fale com a Ouvidoria, o usuário é direcionado para uma página contendo algumas informações sobre o serviço. Para enviar uma mensagem é necessário preencher algumas informações pessoais e informar se quer receber a resposta por e-mail, carta ou por auto-consulta na Internet.

A página do sistema informa que a Ouvidoria não responde a questionamentos relativos aos demais Poderes e nem a questões estaduais ou municipais. Também não são atendidos pedidos de ordem pessoal, assessoria jurídica, insultos, boatos e ameaças. Há em destaque na página do Fale com a Ouvidoria o seguinte texto:

Se você fez alguma solicitação relacionada ao mau funcionamento, irregularidades ou ilegalidades no âmbito das atividades e serviços administrativos da Câmara dos Deputados e não obteve êxito na resposta, exerça a sua cidadania enviando sua mensagem para a Ouvidoria Parlamentar, de acordo com a Lei que regula o acesso à informação pública (Lei $\mathrm{n}^{\circ}$ 12.527/2011).

Nesse caso, há uma confusão entre o papel da Lei no 12.527 de 2011, conhecida como Lei de Acesso à Informação - LAI e o papel da própria Ouvidoria. Se o cidadão fez uma reclamação sobre alguma irregularidade relativa a um dos serviços da Câmara dos Deputados, ele deve enviar mensagem para a Ouvidoria Parlamentar, com base na Resolução que criou a Ouvidoria e não com base na Lei de Acesso à Informação. Afinal, um dos principais papéis da Ouvidoria Parlamentar é examinar reclamações sobre o mau funcionamento dos serviços legislativos e administrativos da Câmara dos Deputados.

Os assuntos mais abordados pelos cidadãos são o processo legislativo (informações sobre tramitação de proposições e sobre o regimento interno da Câmara dos Deputados) e a atuação dos parlamentares (solicitação de informações sobre fatos que chegam ao conhecimento do cidadão pelos meios de comunicação) (CARVALHO, 2008; PAIVA, 2013).

Para Faria (2012), a principal função da Ouvidoria é ser um canal de comunicação entre o cidadão e o órgão responsável pela resolução de um problema. A Ouvidoria oferece escassas possibilidades de participação no processo legislativo e pouco tem contribuído para influenciar a rotina legislativa parlamentar. 
De acordo com Assis (2011), em 2006 e 2007 a Ouvidoria recebeu, respectivamente, 5.403 e 6.877 mensagens, o que representa uma média de pouco mais de 500 mensagens por mês ou aproximadamente 23 mensagens por dia útil. Em outubro de 2013 havia na página da Ouvidoria $^{4}$ o relatório bimestral de mensagens recebidas (referente a fevereiro/março). Nesse período, o Fale com a Ouvidoria recebeu 1.075 mensagens. Desse total, 367 foram finalizadas, 484 foram repassadas, 102 encontram-se pendentes e 122 foram excluídas (BRASIL, 2013c). Entre as mensagens finalizadas, a maior parte se refere a parlamentares e a ouvidoria parlamentar. No primeiro caso, a Ouvidoria diz que "nessas mensagens o cidadão procurou estabelecer contato direto com os seus representantes da Câmara dos Deputados" (BRASIL, 2013c). Porém, se as mensagens foram encaminhadas para a Ouvidoria é porque o contato direto não funcionou e o cidadão está tentando um contato indireto, por meio da Ouvidoria.

No segundo grupo estão as "demandas em que se faz necessária explicação ao cidadão sobre as competências da Ouvidoria. Nesse campo são respondidas demandas enviadas sobre assuntos de fora da competência da Câmara dos Deputados e manifestações de contentamento ou descontentamento de caráter geral” (BRASIL, 2013c). Ou o cidadão não sabe para que serve a Ouvidoria Parlamentar ou, mesmo sabendo a sua finalidade, encontra neste canal uma forma de manifestar-se, sem se importar com as competências e limitações do órgão.

Para Assis (2011), o Fale com a Ouvidoria tem pouca relevância ao se considerar os baixos percentuais de leitura e de resposta das mensagens encaminhadas para os parlamentares. Porém, o programa assume um papel produtivo se for levado em consideração o fato de que o canal estimula o contato com o portal da Câmara e a mobilização de grupos de pressão para a aprovação de determinadas proposições.

O Fale com a Ouvidoria é uma das ferramentas criadas para melhorar a comunicação entre o cidadão e o parlamento. Porém, para que o canal possa obter maior credibilidade, é preciso que todas as mensagens sejam respondidas e em um prazo considerado razoável pelo cidadão.

\subsection{Fale com o Deputado}

Por meio do Fale com o Deputado o usuário pode elogiar, sugerir, solicitar ou reclamar. É preciso escolher um único Deputado e preencher algumas informações pessoais para enviar a mensagem. O preenchimento de um código de segurança tem por objetivo impedir o uso de sistemas para o envio de um grande número de mensagens de forma automática. Na versão anterior do programa, era possível enviar mensagens selecionando todos os Deputados, todos de uma determinada unidade da federação ou todos de um determinado partido (CARVALHO, 2008).

\footnotetext{
${ }^{4}$ Disponível em www.camara.leg.br/a-camara/ouvidoria/historico-e-relatorios.
} 
Esse instrumento deve ser utilizado se o usuário quer encaminhar denúncias, reclamações, sugestões, elogios ou solicitações a um Deputado. Porém, a palavra "denunciar" não é uma das opções oferecidas pelo sistema (BRASIL, 2013b). O usuário envia seu comentário pelo formulário eletrônico e recebe a resposta em sua caixa de e-mail. Porém, essa informação não está claramente formalizada na página da ferramenta. Diferentemente do Fale com a Ouvidoria, não existe um protocolo para acompanhamento da mensagem e não há um prazo para que o Deputado responda a mensagem.

Para Assis (2011), as mensagens enviadas para o Fale com o Deputado, assim como o Fale Conosco limitam-se à ação do emissor, pois não há garantia nem mesmo da recepção por parte dos destinatários, uma vez que não há um registro protocolizado das mensagens. Em sua pesquisa, foi identificado um número muito grande de não respostas às mensagens recebidas. A ausência de respostas é justificada pelo recebimento de demandas de outros estados ou de cidades em que o parlamentar não possui votação expressiva. Além disso, muitas vezes o parlamentar prefere não responder a se envolver em questões polêmicas e não consensuais.

A autora também destaca um tipo de permissividade do serviço, pois enquanto o Fale com a Ouvidoria apresenta o serviço e esclarece o que pode e o que não pode ser encaminhado, no Fale com o Deputado não há qualquer menção sobre o tipo de demanda permitida nesse serviço. Por exemplo, não se nega a possibilidade de envio de demandas de cunho pessoal (ASSIS, 2011).

Santana (2011) destaca alguns pontos importantes em relação ao tratamento de mensagens eletrônicas pelos gabinetes parlamentares. Segundo a autora: a) a maior parte das mensagens é respondida por assessores e raramente encaminhada para os Deputados; b) as mensagens encaminhadas pelo Disque Câmara recebem tratamento prioritário por já terem passado por uma triagem prévia; c) alguns gabinetes armazenam as informações dos usuários em um banco de dados voltado para manutenção de contatos com os eleitores e d) as mensagens não interferem no posicionamento político do parlamentar, pois eles seguem orientações próprias ou dos partidos.

Os gabinetes parlamentares recebem mensagens eletrônicas a partir de três diferentes origens. São mensagens enviadas para a caixa postal do Deputado (dep.nomeparlamentar@camara.leg.br), para o Fale com o Deputado e mensagens encaminhadas pelo Disque Câmara (serviço telefônico gratuito da Câmara dos Deputados). Em 2006 somente o Fale com o Deputado recebeu 4.739.777 mensagens e em 2007 foram mais de 10 milhões (MAIA, 2011). Um total de 10 milhões de mensagens por ano representa uma média de 73 mensagens recebidas por dia útil em cada gabinete parlamentar.

Os funcionários dos gabinetes parlamentares se esforçam para responder às mensagens que chegam em meio eletrônico. Porém, o processo de leitura, triagem, registro e redação da 
resposta dura de 7 a 15 dias em média, conforme a complexidade do assunto e em função do grande número de mensagens recebidas. (SANTANA, 2011).

De acordo com Perna (2010), um dos grandes desafios a ser vencido pelos parlamentos contemporâneos é a sobrecarga de mensagens eletrônicas enviadas para seus endereços eletrônicos.

Nesse mesmo contexto, Stabile (2011) ressalta que, uma das maiores reclamações dos usuários do sítio da Câmara dos Deputados é a falta de atenção dos parlamentares, principalmente em relação aos e-mails não respondidos.

O Fale com o Deputado é uma ferramenta criada para melhorar a comunicação entre o cidadão e o seu parlamentar. É uma ferramenta simples, de fácil entendimento, que permite ao cidadão se expressar livremente sobre qualquer tema. Porém, a falta de resposta dos Deputados às mensagens encaminhadas torna questionável a credibilidade do serviço. Assim como na página da Ouvidoria, o Fale como Deputado deveria informar os assuntos que, a princípio, não seriam respondidos e também dizer que é facultado a cada parlamentar a opção de responder as mensagens que lhe são enviadas.

\subsection{Fale Conosco}

O Fale Conosco deve ser utilizado quando o usuário quer pedir informações gerais, relatar problemas técnicos no portal, ou solicitar pesquisas nos acervos documentais da Câmara dos Deputados (BRASIL, 2013b).

O serviço oferece um formulário eletrônico no qual o usuário preenche algumas informações e envia uma mensagem eletrônica. A mensagem é encaminhada por e-mail para o órgão responsável pelo serviço selecionado. Paiva (2013) destaca que, na primeira versão do serviço Fale Conosco, as mensagens eram recebidas pela Secretaria de Comunicação Social, que fazia uma triagem e as encaminhava para os respectivos setores competentes para prestar o atendimento.

A partir de 2004 a ferramenta passou a integrar boa parte das páginas do sítio da Câmara dos Deputados e as mensagens tornaram-se sensíveis ao contexto, ou seja, são distribuídas automaticamente para os órgãos responsáveis por determinado serviço, de acordo com a página na qual o serviço foi acionado (PAIVA, 2013).

Dessa forma, o Fale Conosco tornou-se um canal de comunicação entre o usuário da Internet e os setores responsáveis por diversos serviços oferecidos pelo portal, sem que o usuário tenha que se dirigir a cada setor por um e-mail específico.

Para incentivar o uso desse serviço como canal de comunicação institucional foi retirado o endereço de $e$-mail e telefones das pessoas e órgãos responsáveis por determinada página ou serviço. 
O nome do serviço também é sensível ao contexto, ou seja, ele sofre alterações de acordo com o perfil da página que oferece o serviço. Por exemplo, ao entrar na página de uma determinada Comissão Permanente, o usuário pode selecionar o serviço Fale com a Comissão que é o Fale Conosco direcionado para aquela Comissão.

Outras vezes o serviço fornece algumas opções de escolha para o usuário. Por exemplo, ao selecionar o Fale Conosco a partir do menu Atividade Legislativa/Legislação, o usuário deverá escolher entre as opções: biblioteca e arquivo, leis federais, orçamento da união, portal, proposições e publicações.

Porém, esse padrão não é adotado em todas as páginas. Por exemplo, ao entrar na página da Procuradoria Parlamentar ou na página da Corregedoria Parlamentar, o usuário tem acesso ao telefone e $e$-mail desses órgãos e não visualiza o Fale Conosco.

Outro problema é a ausência do serviço em diversas páginas do portal. Por exemplo, se o usuário tiver dúvidas sobre o serviço Viagens em missão oficial, que se encontra no menu Transparência, não encontrará o Fale Conosco nessa página. O mesmo acontece com o serviço WebCâmara, disponível no menu Atividade Legislativa, que não possui explicação sobre o que é o serviço e nem como utilizá-lo. Em 2006 o Fale Conosco recebeu 92.091 mensagens (MAIA, 2011), o que representa uma média de 7.674 mensagens por mês ou 348 mensagens por dia útil. Assis (2011) destaca a ausência de compromisso e de prazo de resposta às mensagens recebidas, além da impossibilidade de acompanhamento da tramitação da demanda.

O Fale Conosco cumpre o papel para o qual foi criado, tem contribuído para a disseminação da informação política e para o favorecimento da participação cidadã (PAIVA, 2013). Para melhorar a eficiência do serviço é preciso resolver os problemas relativos à ausência de mecanismos para aferição do tempo de resposta e cobrança sobre mensagens sem resposta ou atendimento.

\subsection{Redes Sociais}

Alguns autores consideram o surgimento da interatividade e colaboração como uma nova fase da Internet, sendo batizada de Web 2.0. Para Cortez (2012), a implantação e popularização da Internet recebe o nome de Web 1.0 enquanto que a Web 2.0 relaciona-se com o surgimento dos sites de colaboração, dos mecanismos de busca como o Google, e nas mídias sociais, como o Facebook, Youtube e Instagram, entre outros.

Ainda de acordo com Cortez (2012), as mídias sociais, apesar de serem as ferramentas mais recentes da Internet, tornaram-se a voz da sociedade e mudaram as relações de comportamento entre as pessoas comuns, agentes públicos e instituições.

Entre as diversas ferramentas de redes sociais, a Câmara dos Deputados possui contas no Facebook e no Twitter, além de dois Blogs. Para Faria (2012), o Twitter é uma plataforma de redes sociais acessada por milhões de pessoas em todo o mundo, um site de relacionamentos 
que conecta pessoas por meio do envio de mensagens curtas (até 140 caracteres). No Twitter foram criadas várias contas diferentes: Agência Câmara, Assessoria de Imprensa, Biblioteca, eDemocracia, Edições Câmara, Plenarinho, Câmara ligada, Rádio Câmara, Relações Públicas, TV Câmara, além de uma conta da Câmara dos Deputados.

Por meio de consulta ao microblog Twitter ${ }^{5}$, é possível verificar que o número de seguidores das contas institucionais é bastante variado. O Twitter da Câmara possui mais de 250 mil seguidores, o da Agência cerca de 80 mil e o da TV Câmara possui 40 mil seguidores. Já a Biblioteca possui somente 251 e o e-Democracia 3.214 seguidores no microblog.

A Câmara dos Deputados possui quatro páginas no Facebook: Câmara dos Deputados, Agência Câmara de Notícias, Biblioteca da Câmara dos Deputados e Editora da Câmara dos Deputados.

De acordo com Perna (2010), o primeiro Blog do portal da Câmara dos Deputados foi desenvolvido pela Comissão de Educação e Cultura, criado em 2008 e descontinuado em 2009. Atualmente a Câmara possui dois Blogs, o blog do programa Câmara Ligada e o blog da Visitação do Congresso Nacional.

O Câmara Ligada é um espaço na Internet para os jovens, desenvolvido a partir de um programa de mesmo nome apresentado pela TV Câmara. É um canal de debate sobre temas polêmicos de interesse da juventude. Já o blog da Visitação é um canal que publica assuntos relativos ao Programa de Visitação do Congresso Nacional, além de notícias sobre exposições, eventos e outros temas de interesse público que estejam em pauta no Congresso.

O portal da Câmara dos Deputados permite que os usuários comentem uma notícia, ou encaminhem o texto para uma conta de e-mail, Orkut, Facebook ou Twitter. Além disso, existe a possibilidade de enviar um comentário para os parlamentares citados em determinada reportagem. Por exemplo, se a matéria faz uma entrevista com dois Deputados sobre determinado tema, ao selecionar a opção "Enviar opinião para os deputados" o comentário do internauta será encaminhado para os dois Deputados citados na matéria.

Além dos canais institucionais, existem diversas contas nas redes sociais mantidas por Comissões e outros órgãos da Câmara dos Deputados. Cada uma dessas contas é mantida de forma descentralizada, para a divulgação de informações e notícias.

Uma preocupação do comitê gestor do portal da Câmara dos Deputados são as citações (retweets) de mensagens enviadas por Deputados e outros perfis de natureza política, uma vez que opiniões pessoais podem ser confundidas com a posição oficial da Câmara. Em função do crescimento do uso do Twitter, o comitê gestor criou um código de conduta com o objetivo de orientar o uso da ferramenta (PERNA, 2010).

\footnotetext{
${ }^{5}$ Disponível em www.twitter.com. Acesso em 25/02/2014. 
Os Deputados também estão atentos à necessidade de fazer parte desses canais de interação e de contato com seus eleitores. Uma consulta ao Twitter utilizando a frase "deputado federal" apresenta como resultado mais de 300 contas ativas. De acordo com Cortez (2012, p. 23):

\begin{abstract}
Aproveitar ao máximo todos os canais midiáticos faz parte da estratégia da maioria dos parlamentares. Não há dúvidas hoje de que a comunicação digital é um dos meios mais poderosos e baratos. Não estar presente nesses espaços é desperdiçar um instrumento eficiente de construção de conhecimento, de interação com suas bases eleitorais e a sociedade em geral; e de auxílio na definição das ações do parlamentar.
\end{abstract}

As redes sociais são utilizadas para a divulgação de informações e notícias sobre programas, projetos e atividades de diversos órgãos da Câmara dos Deputados. Não existem estatísticas consolidadas sobre o alcance institucional das contas nas redes sociais, porém, sabese que essas redes são canais modernos, simples e velozes para a divulgação e disseminação de informações.

\title{
3.8 Sua Proposta Pode Virar Lei
}

Esta opção apresenta dois canais de participação popular relativos ao processo legislativo, os projetos de iniciativa popular e a Comissão de Legislação Participativa - CLP.

Diferentemente das ferramentas anteriores, baseadas na participação por meio da Internet, esses canais de participação apresentam as regras e formulários que possibilitam a real participação do cidadão no processo legislativo por meio da apresentação de um projeto de lei ou de sugestão legislativa.

\subsubsection{Iniciativa Popular}

A apresentação de projetos de iniciativa popular é garantida pela Constituição em seu artigo $61, \S 2^{\circ}$ :

A iniciativa popular pode ser exercida pela apresentação à Câmara dos Deputados de projeto de lei subscrito por, no mínimo, um por cento do eleitorado nacional, distribuído pelo menos por cinco Estados, com não menos de três décimos por cento dos eleitores de cada um deles.

A previsão constitucional da iniciativa popular das leis no Brasil é uma conquista democrática do povo brasileiro em favor da cidadania e da participação política direta (SANTOS, 2009).

O portal da Câmara apresenta um formulário padronizado para a coleta de assinaturas e informa que o projeto deve ser protocolizado junto à Secretaria-Geral da Mesa da Câmara dos Deputados, observado o artigo 252 do Regimento Interno.

Para Santos (2009, p. 89), a forma como foi regulamentado o instituto de participação popular por meio da Lei no 9.709 de 1998 é um indício de que "a maioria dos parlamentares 
brasileiros não tem interesse em viabilizar o exercício da iniciativa das leis no país". Ainda de acordo com Santos (2009), não existe no Brasil lei que tenha surgido a partir de projeto de iniciativa popular e nem mesmo projeto de lei tramitando a partir dessa iniciativa. Formalmente, os projetos que supostamente seriam de iniciativa popular foram validados na Câmara dos Deputados pela assinatura de um deputado ou pelo Presidente da República.

O maior empecilho para os projetos de iniciativa popular é o grande número de assinaturas oriundas de cinco estados diferentes, além da inviabilidade de conferência das assinaturas e demais dados requeridos pelo Regimento Interno da Câmara dos Deputados (NERY, 2001; ROLIM, 2005; CARVALHO, 2008; TEIXEIRA, 2008; SANTOS, 2009).

Para Teixeira (2008), a apresentação de um projeto de lei de iniciativa popular fica limitada à existência de organizações muito bem estruturadas, dotadas de grande capacidade de penetração na opinião pública e de fartos recursos materiais.

Trata-se da possibilidade de iniciativa popular para a apresentação de proposição legislativa a partir de um formulário publicado na página da Câmara dos Deputados. Porém, mesmo com a coleta de um grande número de assinaturas, o projeto não possui caráter imperativo, estando sujeito ao processo legislativo ordinário.

\subsubsection{A Comissão de Legislação Participativa}

A Comissão de Legislação Participativa da Câmara dos Deputados (CLP) foi criada por meio de Resolução $\mathrm{n}^{\circ} 21$, de 30 de maio de 2001, com o objetivo de receber sugestões legislativas da sociedade civil organizada, que se faz representar por meio de associações, sindicatos, entidades, órgãos de classe e organizações não governamentais, exceto partidos políticos (BRASIL, 2001a).

As sugestões aprovadas pela CLP se transformam em proposições de autoria da Comissão e passam a tramitar em regime de prioridade na Câmara dos Deputados. De acordo com Nery (2001), a CLP é um instrumento inovador criado para responder um dos maiores desafios enfrentado pelas democracias contemporâneas: o desafio da participação e cidadania.

A função primordial da Comissão de Legislação Participativa é estabelecer uma aproximação entre a sociedade e o Legislativo (ANDRADE, 2003; ASSIS, 2010; ROLIM, 2005; COUTO, 2007; QUEIROZ, 2011).

Carvalho (2008) acredita que a criação da CLP foi um avanço democrático, principalmente quando são comparados os números de sugestões apresentadas à Comissão com o número de projetos de iniciativa popular. Até o final de 2007 foram apresentadas três proposições de iniciativa popular e 603 sugestões foram recebidas pela CLP.

Do total de sugestões recebidas de 2001 a novembro de 2007, 96 foram convertidas em projetos de lei e somente um foi convertido em lei. O PL n ${ }^{\circ} 5.828$ de 2001, oriundo de sugestão 
da Associação dos Juízes Federais do Brasil, deu origem à Lei $\mathrm{n}^{\circ}$ 11.419, de 2006, que dispõe sobre a informatização do processo judicial (COUTO, 2007; TEIXEIRA, 2008).

Santos (2009) destaca que a criação da CLP pode ser vista como uma alternativa à participação popular junto ao Poder Legislativo, mas também pode ser analisada como um artifício parlamentar criado para reforçar a representação política. Para Santos (2009), as principais funções da CLP são estimular a mobilização social, aproximar representantes e representados e incentivar a apresentação direta das demandas legislativas da sociedade junto às Casas Legislativas. O modelo federal foi replicado em doze Assembleias Legislativas Estaduais e em quarenta Câmaras Municipais (QUEIROZ, 2011).

A criação da CLP estimulou a participação direta da sociedade na elaboração legislativa, mas os números demonstram que muito ainda tem que ser feito para que se diminua a enorme distância entre o povo e os legisladores (ANDRADE, 2003; ROLIM, 2005).

Queiroz (2011) assevera que o trabalho da CLP não se restringe à criação de proposições. A Comissão é uma tribuna que dá voz às entidades representantes de movimentos sociais e de minorias ao promover audiências e debates sobre diversos temas. Portanto, o êxito da comissão não deve ser medido pelo número de leis aprovadas e sim pela contribuição oferecida pelo colegiado para o debate político.

O número de vagas dos membros da CLP alterou-se ao longo de sua existência. Em 2001 eram trinta e uma vagas, em 2002 o número foi reduzido para vinte e cinco, e em 2004 passou para dezoito. As sucessivas reduções demonstram certo desinteresse de grande parte dos parlamentares por essa Comissão (COUTO, 2007).

Apesar dos avanços, a maioria dos parlamentares demonstra pouco interesse em apreciar as iniciativas da sociedade. Por exemplo, de 2002 a 2005 pelo menos um terço das vagas da Comissão permaneceram sem indicação de parlamentares para ocupá-las (SANTOS, 2009). No início de cada ano os partidos escolhem as presidências das Comissões com base no critério da proporcionalidade partidária. Desde 2002, a presidência da CLP é sempre uma das últimas opções de escolha dos partidos (QUEIROZ, 2011). Para Teixeira (2008), a CLP tem um enorme potencial ainda não aproveitado, como agente capaz de reduzir a distância entre a população e seus representantes.

A Comissão de Legislação Participativa é considerada um avanço democrático ao possibilitar a apresentação de sugestões, que podem se transformar em proposições legislativas, por parte de entidades representantes da sociedade civil. Porém, pelos resultados apresentados até o momento, o êxito da Comissão pode ser medido mais pela oportunidade de ser um canal de debate do que pelas proposições que se transformaram em leis. 


\section{Conclusões}

A Câmara dos Deputados oferece várias ferramentas de participação e de interação, com o objetivo de aproximar a sociedade do parlamento. Cada uma dessas ferramentas vem sendo aprimorada para tornar mais fácil o acesso e a participação dos cidadãos, independente da formação e do conhecimento sobre política ou sobre o processo legislativo.

Afinal, "quanto maior o número de canais abertos entre a sociedade e os poderes instituídos, maiores as chances de prosperidade da democracia participativa e de concretização do ideal da soberania popular" (TEIXEIRA, 2008, p. 57).

A oferta de ferramentas e canais de participação precisa vir acompanhada da disposição dos Deputados e assessores de participarem desse processo, caso contrário a expectativa gerada pode ocasionar frustrações para os cidadãos que aguardam a manifestação dos parlamentares. Nesse caso, é preciso que a instituição avalie constantemente os diversos canais e também as condições oferecidas para que os Deputados e suas equipes possam atuar satisfatoriamente.

Apesar da existência de diversos canais voltados para a participação do cidadão, de um modo geral, são maneiras diferentes para o recebimento de informações e o envio de sugestões e críticas. As possibilidades reais de interferência do cidadão no processo legislativo são praticamente nulas (MARQUES, 2010; ASSIS, 2011; NAKAMURA, 2013).

O modelo apresentado por Silva (2011) permite visualizar a distribuição das ferramentas de participação entre os três requisitos democráticos e respectivas dimensões qualitativas, conforme apresentado no Quadro 2.

Quadro 2 - Requisitos democráticos e dimensões das ferramentas de participação da Câmara dos Deputados

\begin{tabular}{|c|c|c|c|}
\hline & Publicidade & Responsividade & Porosidade \\
\hline Utilitário & $\begin{array}{c}\text { Fale com a } \\
\text { ouvidoria, Fale } \\
\text { com o Deputado, } \\
\text { Fale conosco }\end{array}$ & - & - \\
\hline Informativo & $\begin{array}{c}\text { Redes sociais, } \\
\text { Iniciativa Popular, } \\
\text { Comissão de } \\
\text { Legislação } \\
\text { Participativa } \\
\end{array}$ & $\begin{array}{c}\text { Fale com a ouvidoria, } \\
\text { Fale com o Deputado, } \\
\text { Fale conosco }\end{array}$ & Enquetes, Redes sociais \\
\hline Instrutivo & $\begin{array}{l}\text { Bate-papo, } \\
\text { Enquetes }\end{array}$ & Enquetes, Redes sociais & $\begin{array}{c}\text { Bate-papo, Fale com a } \\
\text { ouvidoria, Fale com o } \\
\text { Deputado, Fale conosco }\end{array}$ \\
\hline Argumentativo & $\begin{array}{l}\text { Debates no } e \text { - } \\
\text { Democracia }\end{array}$ & $\begin{array}{c}\text { Bate-papo, Debates no } \\
\text { e-Democracia, } \\
\text { Iniciativa Popular, } \\
\text { Comissão de Legislação } \\
\text { Participativa }\end{array}$ & $\begin{array}{c}\text { Debates no } e- \\
\text { Democracia, Iniciativa } \\
\text { Popular, Comissão de } \\
\text { Legislação Participativa }\end{array}$ \\
\hline $\begin{array}{l}\text { Processo } \\
\text { decisório }\end{array}$ & não se aplica & não se aplica & - \\
\hline
\end{tabular}

Fonte: Adaptado pelo autor, de Silva (2011) 
As ferramentas estão distribuídas entre as três dimensões, o que caracteriza uma preocupação com a transparência, com o diálogo e com o recebimento de sugestões por parte dos cidadãos. Porém, nenhuma delas garante que a participação do cidadão será levada em consideração no momento da elaboração legislativa.

Por essa razão, identifica-se que a utilização de ferramentas digitais de participação contribui para o sistema democrático, uma vez que proporciona certo grau de debate, troca de informações, mais transparência e consequentemente maior possibilidade de controle social. Porém, essas ferramentas ainda mantém o poder decisório nas mãos dos representantes ao não permitir a transferência de parte do processo de decisão para o cidadão.

Entre vários desafios que se apresentam em relação à participação popular, destacam-se: a) a necessidade de tornar o processo legislativo de fácil compreensão para que mais pessoas possam entender e participar do processo e; b) uma forma de levar as opiniões, críticas e sugestões para dentro da esfera de decisão, para o conhecimento dos Deputados.

Em relação ao primeiro desafio, é preciso investir no leiaute das ferramentas de participação e integração com as áreas de notícias e processo legislativo do portal institucional para tornar a comunicação mais acessível ao cidadão comum, que não é especialista em processo legislativo.

Deve-se ressalvar que a participação massiva de pessoas é menos importante que a garantia da oferta de oportunidades de participação, pois a democracia também pressupõe a liberdade de escolha sobre participar ou não de determinada discussão.

Para Assis (2011) o sítio da Câmara dos Deputados estimula fortemente a participação popular, porém, essa participação é limitada pela necessidade de domínio de conhecimento técnico, de existência de capacidade argumentativa e de domínio da escrita e da Internet.

O segundo desafio é bem mais complexo, uma vez que não se trata de uma discussão tecnológica e sim do debate entre os limites da democracia representativa e a possibilidade de criação de mecanismos que possibilitem a realização de experiências com características de democracia direta.

Se as ferramentas digitais não substituem outras formas de ativismo cívico, tais como abaixo-assinados, manifestações públicas, participação em organizações não governamentais, partidos políticos, audiências públicas, etc., espera-se que possam incrementar as possibilidades de participação do cidadão, seja de forma individual ou em grupos representativos de opinião das maiorias e também das minorias.

Nesse sentido, Maia (2011) apresenta a hipótese de que o maior problema das democracias liberais contemporâneas talvez não esteja na participação e sim na baixa capacidade de o cidadão influir individualmente na agenda política, em face da concorrência com o sistema político, instâncias de vários campos sociais (econômicas, religiosas, etc.) e 
corporações sociais (organizações da sociedade civil), que na maioria das vezes privilegiam o interesse do grupo sobre o interesse civil ou republicano.

A transformação da sociedade contemporânea em sociedade da informação tem produzido novos desafios nas mais diversas áreas, inclusive na esfera política. A nova conjuntura social aliada ao potencial inovador das tecnologias digitais tem pressionado o poder público a rever conceitos e a criar mecanismos voltados para o fortalecimento da cidadania.

É exatamente por meio da participação, utilizando-se de mecanismos tradicionais e virtuais, que a nova sociedade moldará seus representantes para que aumentem cada vez mais o nível qualitativo de comunicação entre a esfera pública e a esfera política no sentido de maior participação efetiva do cidadão no processo decisório político.

\section{Referências}

ANDRADE, Aparecida de Moura. A participação da sociedade civil no processo legislativo: a contribuição da Comissão de Legislação Participativa da Câmara dos Deputados. 2003. 69 f. Trabalho de Conclusão de Curso (Especialização em Gestão Legislativa) - Faculdade de Estudos Sociais Aplicados, Universidade de Brasília, Brasília, 2003.

ASSIS, Erika Maria Bastos de. A política polissêmica: fazeres, dizeres e silêncio nos programas Fale com o Deputado e Fale com a Ouvidoria da Câmara dos Deputados. 2011. 316 f. Tese (Doutorado em Ciência Política) - Instituto de Estudos Sociais e Políticos, Universidade do Estado do Rio de Janeiro, Rio de Janeiro, 2011.

ASSIS, Nilson Rodrigues de. $\mathrm{O}$ uso da internet como instrumento eficaz de democracia e participação popular: análise de sua aplicação na Câmara dos Deputados. 2010. 62 f. Trabalho de Conclusão de Curso (Especialização em Gestão Pública e Responsabilidade Fiscal), Escola Superior Aberta do Brasil, Vila Velha, 2010.

BARBOSA, Alexandre Fernandes; CAPPI, Juliano; GATTO, Raquel. Os caminhos para o avanço do governo eletrônico no Brasil. In: Comitê Gestor da Internet no Brasil. Pesquisa sobre o uso das tecnologias da informação e da comunicação 2008. São Paulo: Editora, 2009.

BRASIL. Câmara dos Deputados. Resolução no 19 de 2001. Cria a Ouvidoria Parlamentar e dá outras providências. Diário da Câmara dos Deputados. Brasília, 15 mar. 2001. Disponível em: <http://www2.camara.leg.br/legin/int/rescad/2001/resolucaodacamaradosdeputados-19-14marco-2001-321167-publicacaooriginal-1-pl.html>. Acesso em: 24 set. 2013.

BRASIL. Câmara dos Deputados. Ato da Mesa no 21 de 30 de maio de 2001. Cria a Comissão de Legislação Participativa. Diário da Câmara dos Deputados. Brasília, 31 mai 2001. Disponível em: <http://www2.camara.leg.br/legin/int/rescad/2001/resolucaodacamaradosdeputados-21-30maio-2001-319754-publicacaooriginal-1-pl.html>. Acesso em: 13 out. 2013.

BRASIL. Câmara dos Deputados. Ouvidoria parlamentar: O que é? Para que serve? Brasília: Câmara dos Deputados, Edições Câmara, 2010. 48 p. - (Série ação parlamentar; n. 412).

BRASIL. Câmara dos Deputados. Ato da Mesa $\mathbf{n}^{0} 58$ de 2013. Estabelece diretrizes para a Gestão do Relacionamento da Câmara dos Deputados com a sociedade, de forma não presencial, e dá outras providências. Diário da Câmara dos Deputados. Brasília, 09 jan. 2013. Disponível em: <http://www2.camara.leg.br/legin/int/atomes/2013/atodamesa-58-8-janeiro2013-775040-publicacaooriginal-138697-cd.html> Acesso em: 24 set. 2013. 
BRASIL. Câmara dos Deputados. Fale com o Deputado. Disponível em: <http://www2.camara.gov.br/participe/fale-conosco/fale-com-o-deputado>. Acesso em: 23 set. 2013.

BRASIL. Câmara dos Deputados. Fale com a Ouvidoria. Disponível em: <http://www2.camara.leg.br/a-camara/ouvidoria>. Acesso em: 08 out. 2013.

BRASIL. Câmara dos Deputados. Participe. Disponível em: <http://www2.camara.leg.br/participe>. Acesso em: 21 set. 2013.

BRASIL. Câmara dos Deputados. Portal e-Democracia. Disponível em: <http://edemocracia.camara.leg.br>. Acesso em 08 out. 2013.

BRASIL. Lei $\mathbf{n}^{0} 12.527$ de 18 de novembro de 2011. Regula o acesso à informações. Disponível em: < http://www.planalto.gov.br/ccivil_03/_ato2011-2014/2011/lei/112527.htm>. Acesso em 23 fev. 2014.

CARVALHO, Alexandro Gomes da Silva. A participação popular na Câmara dos Deputados frente às novas tecnologias. 2008. $87 \mathrm{f}$. Trabalho de Conclusão de Curso (Especialização em Processo Legislativo) - Centro de Formação, Treinamento e Aperfeiçoamento da Câmara dos Deputados (Cefor), Brasília, 2008.

CORTEZ, Camila Gonzaga. Como aumentar a visibilidade e a credibilidade do parlamentar por meio das mídias sociais? 2012. 92 f. Trabalho de Conclusão de Curso (Especialização em Política e Representação Parlamentar) - Centro de Formação, Treinamento e Aperfeiçoamento (Cefor), Brasília, 2013.

COUTO, Amilcar Amaral. Comissão de Legislação participativa da Câmara dos Deputados: participação da sociedade civil organizada na elaboração das leis orçamentárias anuais de 2002 a 2006. 2007. 69 f. Trabalho de Conclusão de Curso (Especialização em Processo Legislativo) - Centro de Formação, Treinamento e Aperfeiçoamento (Cefor), Brasília, 2007.

FARIA, Cristiano Ferri Soares de. O parlamento aberto na era da internet: pode o povo colaborar com o Legislativo na elaboração das leis? - Brasília: Câmara dos Deputados, Edições Câmara, 2012. 334 p. - (Série temas de interesse do Legislativo; n. 18).

GOMES, Wilson; MAIA, Rousiley C.M. Comunicação e democracia: problemas \& perspectivas. São Paulo: Paulus, 2008.

MAIA, Rousiley Celi Moreira; GOMES, Wilson; MARQUES, Francisco Paulo Jamil Almeida (Org.). Internet e participação política no Brasil. Porto Alegre: Editora Meridional, 2011.

MARQUES, Francisco Paulo Jamil Almeida. Internet, canais de participação e efeitos políticos: um estudo do Portal da Câmara. Revista Fronteiras: estudos midiáticos, São Leopoldo, v. 2, n. 12, p.82-94, 01 mai. 2010. Disponível em: 〈http://www.fronteiras.unisinos.br/pdf/89.pdf>. Acesso em: 05 out. 2013.

NAKAMURA, Paula Mari Mikai. O atendimento ao cidadão e o portal da Câmara dos Deputados. Dissertação (Mestrado em Ciência da Informação) - Instituto Brasileiro de Informação em Ciência e Tecnologia, Universidade Federal do Rio de Janeiro, Rio de Janeiro, 2013.

NERY, Carlos Alberto Farias. A iniciativa popular na elaboração legislativa: um estudo sobre a participação da sociedade no processo de formulação das leis. 2001. $98 \mathrm{f}$. Trabalho de Conclusão de Curso (Especialização em Desenvolvimento Gerencial) - Faculdade de Estudos Sociais Aplicados, Universidade de Brasília, Brasília, 2001.

PAIVA, Christiane Coelho. O Programa Fale Conosco da Câmara dos Deputados: é possível participar e interagir? 2009. $91 \mathrm{f}$. Trabalho de Conclusão de Curso (Especialização em Instituições e Processos Políticos do Legislativo) - Centro de Formação, Treinamento e Aperfeiçoamento (Cefor), Brasília, 2013. 
PERNA, Andrea Sampaio. O lado invisível da participação política: gestão da informação dos mecanismos digitais de participação política nos parlamentos da América Latina, com uma análise da Câmara dos Deputados do Brasil. 2010. 269 f. Dissertação (Mestrado em Ciência da Informação) - Faculdade de Ciência da Informação, Universidade de Brasília, Brasília, 2010.

QUEIROZ, Marcos Augusto de. Dez anos de CLP: legislação participativa ou participação legislativa? 2011. 50 f. Trabalho de Conclusão de Curso (Especialização em Processo Legislativo) - Centro de Formação, Treinamento e Aperfeiçoamento (Cefor), Brasília, 2011.

ROLIM, Éricka Sobreira Lucena. A Comissão de Legislação Participativa da Câmara dos Deputados e a flexibilização da iniciativa popular. 2005. $51 \mathrm{f}$. Trabalho de Conclusão de Curso (Especialização em Gestão Legislativa) - Faculdade de Estudos Sociais Aplicados, Universidade de Brasília, Brasília, 2005.

SANTANA, Dinajara Daniel Figueiredo. Uso das informações da Central de Comunicação Interativa da Câmara dos Deputados pelos gabinetes parlamentares. 2011. $82 \mathrm{f}$. Trabalho de Conclusão de Curso (Especialização em Gestão Pública Legislativa) - Centro de Formação, Treinamento e Aperfeiçoamento (Cefor), Brasília, 2011.

SANTOS, Luiz Cláudio Alves dos. A participação popular na iniciativa das leis no contexto da democracia representativa e da participação política no Brasil. 2009. 144 f. Dissertação (Mestrado em Ciência Política) - Instituto de Pesquisas Universitárias do Rio de Janeiro, Rio de Janeiro, 2009.

SILVA, Sivaldo Pereira da. In: MAIA, Rousiley Celi Moreira; GOMES, Wilson; MARQUES, Francisco Paulo Jamil Almeida (Org.). Internet e participação política no Brasil. Porto Alegre: Editora Meridional, 2011.

STABILE, Max. Democracia eletrônica para quem: quem são, o que querem e como os cidadãos avaliam o portal da Câmara dos Deputados. Brasília, 2012. 185 f. Dissertação (Mestrado em Ciência Política) - Instituto de Ciência Política, Universidade de Brasília, 2012.

TEIXEIRA, Leandro Arantes. A iniciativa popular de lei no contexto do processo legislativo: problemas, limites e alternativas. 2008. 67 f. Trabalho de Conclusão de Curso (Especialização em Processo Legislativo) - Centro de Formação, Treinamento e Aperfeiçoamento (Cefor), Brasília, 2008.

Artigo recebido em: 02/11/2013

Artigo aceito para publicação em: 13/03/2014 